\title{
Early access microseismic monitoring using sensors installed in long boreholes
}

\author{
by T. Butler* and B. Simser ${ }^{\dagger}$
}

\section{Synopsis}

For deep mines where a microseismic monitoring programme will be implemented, one of the obstacles during the early stages of mine development is how to obtain adequate three-dimensional microseismic monitoring coverage with minimal access to the rock volume. The ability to utilize existing or planned exploration or geological boreholes for seismic sensor placement is offered as a cost-effective solution to this problem. For existing mines planning to mine new, deeper ore zones, the ability to install seismic sensors in long boreholes is especially important where long ramps are being developed in high-stress/burst-prone ground where rockbursting could be expected and microseismic monitoring is required as part of a comprehensive ground control safety programme. Lessons learned from the installation and operation of seismic systems at Glencore's Nickel Rim South and Fraser Morgan mines are presented and suggested strategies for establishing new seismic monitoring systems at new mines are discussed. A case study is presented from Glencore's Nickel Rim Deep Project in Sudbury, Ontario, Canada showing how seismic sensors installed in subhorizontal geological 'scout-holes' drilled ahead of the ramp development end are being used for monitoring ramp and infrastructure development of a new mining zone in deep high-stress ground.

Keywords

microseismicity, three-dimensional monitoring, longhole sensors.

\section{Introduction}

Establishing microseismic monitoring for mines early in the mine development cycle is important from a worker safety perspective, but early seismic monitoring can also provide valuable information about the nature of the rock mass response to mining when little other rock mass data exists. Seismic information can help identify the seismic nature of different geological units in the rock mass, and may also help determine the location and nature of existing geological discontinuities. The recording of microseismicity early in the mine's life is often the first type of 'deformation feedback' from the rock mass available to the ground control engineer, and the seismic information collected in early stages of mine development can enhance the accuracy of numerical models (Beck and Brady, 2001).

One of the major obstacles to the early deployment of a seismic monitoring system is the perceived lack of access for sensor (geophone or accelerometer) installation. For seismic systems to provide accurate source locations and source parameters, good threedimensional (3D) spatial positioning of the sensors is usually required, preferably with sensors located around and within the volume of rock mass being monitored. In general, most seismic sensors in new mining areas are installed only after development levels have been established and drill rigs can be positioned to drill short sensor holes, usually just deep enough to ensure good contact beyond the fracture zone. The lack of an adequate number of sensors and/or adequate spatial positioning in the early days of mining will result in inferior seismic monitoring coverage until much later in the mine development cycle when more access is available and additional sensors can be installed.

A basic history of seismic system network deployment for Glencore's Nickel Rim South (NRS) mine and the Fraser Morgan mine is presented, highlighting some lessons learned. This experience, coupled with advances in sensor installation techniques, has resulted in a new strategy of installing sensors in long boreholes to provide early seismic monitoring coverage, initially for safety purposes. This strategy was employed successfully to monitor the first deep-level ramp development for the Nickel Rim Deep (NRD) project from May 2014 to November 2016. Details of this project are presented. The same technique, with some improvements based on knowledge gained from the NRD monitoring project, is being used to provide seismic monitoring coverage for ramp development at Glencore's new

* Engineering Seismology Group (ESG) Canada Inc., Canada.

+ Sudbury Integrated Nickel Operations, A Glencore Company, Canada.

(C) The Southern African Institute of Mining and Metallurgy, 2018. ISSN 2225-6253. This paper was first presented at the AfriRock 2017 International Symposium, 30 September -6 October 2017, Cape Town Convention Centre, Cape Town. 


\section{Early access microseismic monitoring using sensors installed in long boreholes}

Onaping Depth project (ODP), which started in February 2017. For both projects, the ramp sensors will be used as the starting point for new seismic monitoring arrays to cover additional mine infrastructure development, shaft sinking, and initial mining operations.

\section{Seismic monitoring at Glencore's Sudbury Integrated Nickel Operations}

\section{Nickel Rim South Mine}

The NRS mine is a nickel/copper operation located in the Sudbury Basin in Ontario, Canada. Stoping operations began in May 2009. Details of the ESG seismic monitoring system installed at NRS and some practical applications can be found in Simser et al. (2015) and Simser and Butler (2016). The seismic monitoring programme started in January 2009 with the initial sensors deployed in early development drives. Figure 1 shows the seismic array, with sensor locations as of 2013. The sensors include a mixture of uniaxial accelerometers $(50 \mathrm{~Hz}$ to $2.5 \mathrm{kHz}$ ) and $15 \mathrm{~Hz}$ triaxial geophones. The $15 \mathrm{~Hz}$ geophones were incrementally added starting in 2010 to provide improved dynamic range. As mining progressed, the NRS seismic array benefitted from both hangingwall and footwall access that provided reasonable 3D coverage of the mining zones. In late 2016 the seismic array consisted of 57 working sensors (21 triaxial $15 \mathrm{~Hz}$ geophones and 36 uniaxial accelerometers) with an average sensor spacing of $150 \mathrm{~m}$. This combination of sensors results in good seismic coverage within the moment magnitude range of -2 to +2 (Simser and Butler, 2016). In addition, $4.5 \mathrm{~Hz}$ geophones placed in the far field are used for large event magnitude estimates as well as for correlation to the Sudbury Regional Seismic Network (Hudyma and Beneteau, 2010). Array sensor density is highest in the west flank of the orebody, where sensors were installed in first access development from 2007 to 2009.

\section{Fraser Morgan Mine}

The Fraser Morgan mine is a blast-hole nickel operation offset a few kilometres from the narrow-vein Fraser copper mine in the Sudbury basin in Ontario, Canada, and is located about $70 \mathrm{~km}$ west of NRS. Both Fraser mines are accessed via the same shaft system and each mine has its own seismic monitoring system. The Fraser Morgan mine seismic system currently monitors seismic activity from two distinct mining zones between 1000 and $1500 \mathrm{~m}$ below surface. The array started recording seismic events in May 2013, and has been incrementally expanded as mine development has progressed.

Figure 2a shows a plan view of the Fraser Morgan mine 39-2 level development horizon at $1200 \mathrm{~m}$ depth, with the seismic sensors plotted as they existed in 2014. The seismic system consisted of seven triaxial $15 \mathrm{~Hz}$ geophones and three uniaxial $15 \mathrm{~Hz}$ geophones that were installed in development that was available at the time. Unfortunately, development access was only available from the geological footwall side of the orebody, resulting in a seismic array that was largely planar in nature, with most active mining being outside the array. Figure $2 \mathrm{~b}$ shows the exploration boreholes that had been drilled at Fraser Morgan mine. Figure 2c shows a comparison of seismic event and orepass noise locations at Fraser Morgan 11 zone from 2014 and 2016. In 2016, the seismic system had expanded to nine triaxial $15 \mathrm{~Hz}$ geophones, nine uniaxial $15 \mathrm{~Hz}$ geophones, five uniaxial accelerometers ( $50 \mathrm{~Hz}$ to $2.5 \mathrm{kHz}$ ), and two $4.5 \mathrm{~Hz}$ strong ground motion geophones. The reduction in event location scatter in 2016 is clearly evident and is due largely to the enhanced seismic array that provided better 3D coverage and improved event location accuracy. This example illustrates the importance of installing a sufficient number of sensors in a new mining area and having good 3D distribution of these sensors so that accurate seismic event locations are possible.

In hindsight, it would have been possible to install sensors in the long exploration/orebody delineation boreholes drilled from early development drives or in boreholes drilled specifically for the sensors prior to the start of mining in May 2013. Once a drill rig is in place, it is not a large cost to drill a second hole if required. Fraser Morgan mine is in the process of installing several additional sensors in long boreholes to help improve the 3D coverage of the seismic monitoring array.

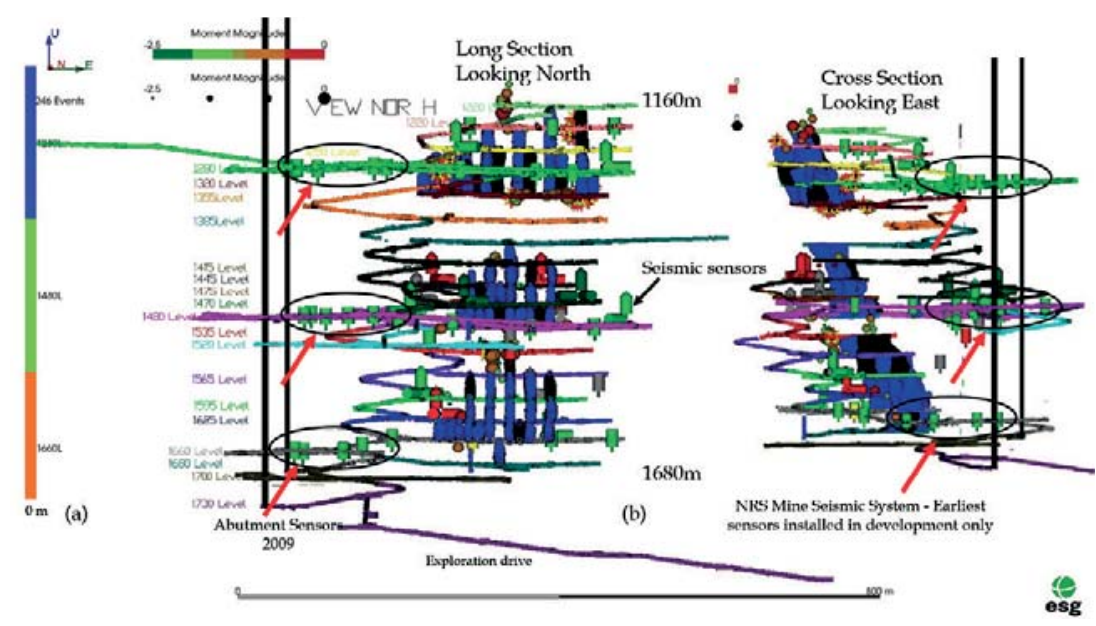

Figure 1-Long section (a) and cross-section (b) of Glencore's Nickel Rim South mine showing mined stopes as of $2013.5 .3 \mathrm{~m}(\mathrm{H}) \times 5.0 \mathrm{~m}(\mathrm{~W}) \mathrm{mine}$ development is shown in multi-colours. Seismic sensors are shown with exaggerated symbols in green. Red arrows/black circles indicate the initial sensor locations in early development tunnels in 2009 


\section{Early access microseismic monitoring using sensors installed in long boreholes}

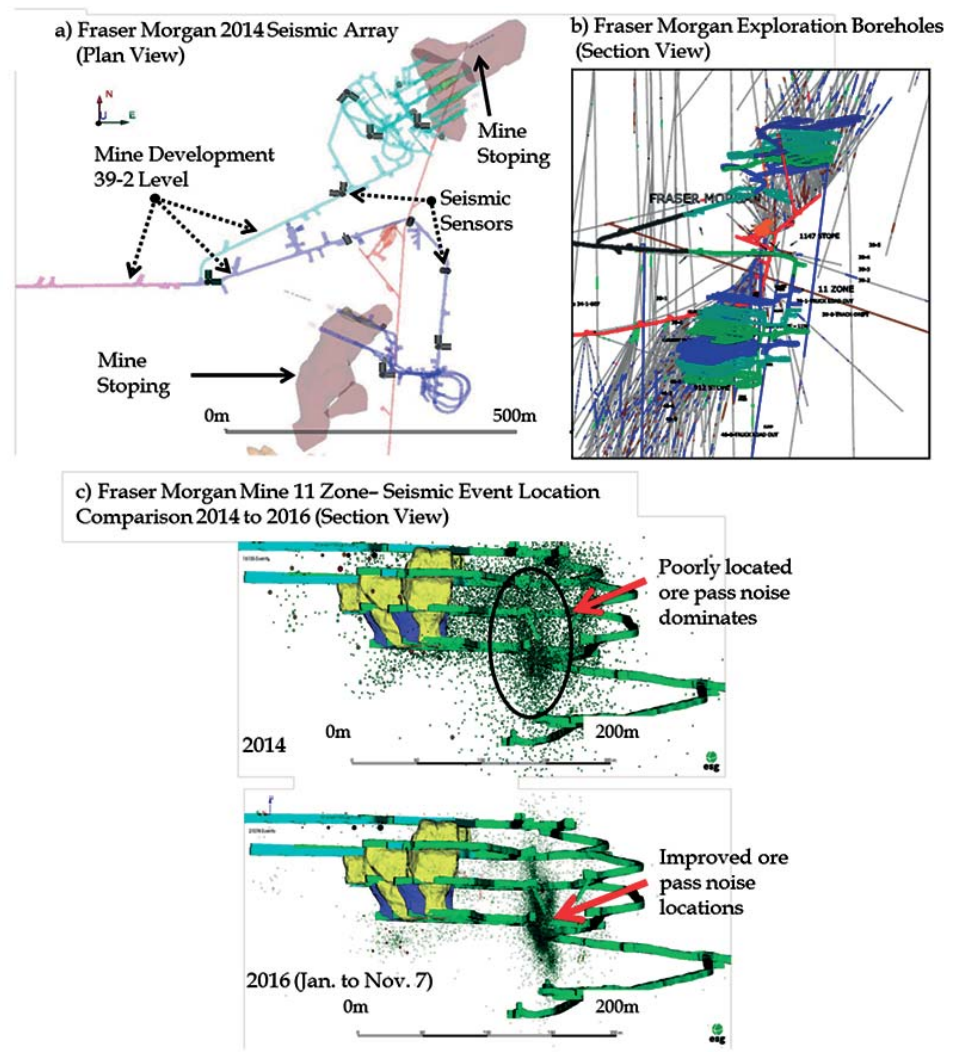

Figure 2-(a) Fraser Morgan seismic array and mining layout at the 39-2 level (1200 m below surface) in 2014, with mining located mostly outside the seismic array. (b) Available exploration boreholes (grey lines) at Fraser Morgan mine that could have been used for sensor installation. (c) Seismic data recorded in Fraser Morgan mine 11 zone during 2014 when the seismic array was planar in nature, compared to data recorded from January 1 to November 7, 2016 with the improved array

The above examples from NRS and Fraser Morgan show the typical life-cycle of deploying a seismic system for new mines. Sensors are installed in short boreholes, only from early development drives, simply because this is generally considered to be the first opportunity to access the rock mass. This approach greatly limits the seismic monitoring array to sensor positions that will rarely be ideal for good, or even adequate, seismic coverage during the early stages of mining. In reality, first access to the rock mass is usually provided by exploration boreholes. These boreholes can often provide a complete 3D opportunity for seismic sensor placement around the orebody and future mining zones.

\section{New approach to establishing early seismic monitoring}

Experience gained from establishing the seismic monitoring networks in the Sudbury area suggests that long borehole sensors could be used to monitor seismicity for development and for early establishment of mine-wide seismic monitoring arrays for new mining areas. The future for Glencore mining in the Sudbury area includes two new deep-level projects being accessed from existing Glencore mining infrastructure. These include the NRD project that is being accessed from the NRS mine and the ODP project to be accessed from existing Craig mine infrastructure. Details of the NRD project are presented. Lessons learned from the NRD project are being applied to seismic monitoring for the ODP ramp development, which is very similar in nature to the NRD ramp.

\section{Nickel Rim Deep Project - overview}

The conceptual layout for the NRD ramp and early mining infrastructure required to access two copper orebodies located between approximately $2500 \mathrm{~m}$ and $2900 \mathrm{~m}$ below surface is shown schematically in Figure 3 . A $5 \mathrm{~m}$ wide $\times 5.3 \mathrm{~m}$ high exploration ramp/drift was driven $2.3 \mathrm{~km}$ from east to west, starting at the 1660 level (1660 m below surface) at NRS, from May 2014 to November 2016. The ramp was planned at a $15 \%$ grade to reach a maximum depth of $1965 \mathrm{~m}$ at the western end of the development drift. The end of the ramp will be the starting point for infrastructure to support mining the deeper deposit via an internal shaft. Face advance was planned at $4 \mathrm{~m}$ per day. A twin of the decline ramp started in January 2017 and is located $30 \mathrm{~m}$ south of the initial ramp.

Historically, Sudbury operations have encountered significant rockbursting in development far from mining. Post-incident investigations found that these bursts were usually associated with high and/or abnormal stress conditions caused by locally complex geology and/or geological structures. It was known that the NRD ramp would intersect several different rock types and several geological structures, including the Victor Shear striking southsoutheast with $300 \mathrm{~m}$ apparent left-lateral movement. As a 


\section{Early access microseismic monitoring using sensors installed in long boreholes}

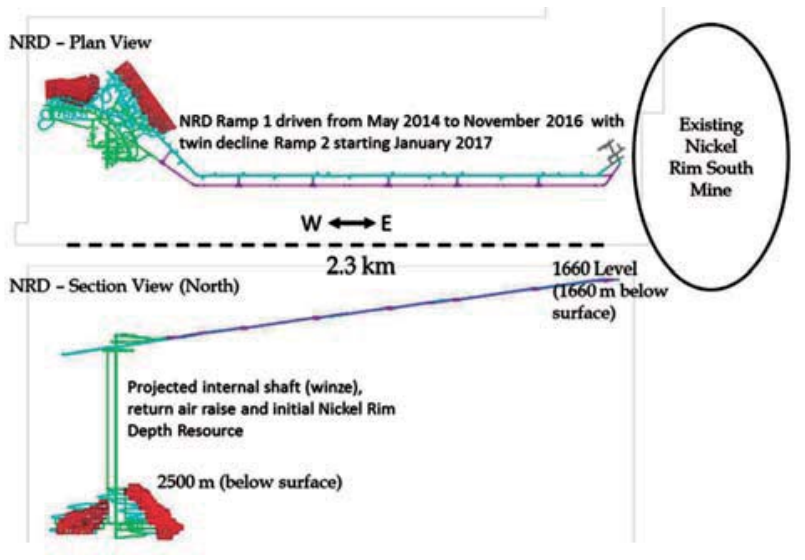

Figure 3-The NRD deposit will be accessed via twinned ramps driven from the existing NRS mine at the 1660 level. The plan is to access the ore zone at $2500 \mathrm{~m}$ below surface via an internal shaft (winze)

result, Glencore decided to develop a standardized process to evaluate the potential conditions of new mining areas prior to development. The geological part of this process involved drilling approximately $600 \mathrm{~m}$ long subhorizontal $\left(-9^{\circ}\right.$ to $-14^{\circ}$ dip) 'scout-holes' (NQ/76 mm outside diameter) from the ramp out ahead of the face. The scout-holes were collared every $300 \mathrm{~m}$ along the drift and were drilled from truck turnaround cut-outs in the ramp. Drill core was obtained and logged for geological and geotechnical properties. Acoustic and optical televiewer instrumentation was pulled along the length of each uncased borehole to image the hole and obtain detailed fracture locations and orientations. The probes were attached to a $1 / 4$ inch Kevlar rope threaded through a pulley that was anchored with a brush assembly installed at the bottom of the hole. It took approximately one hour to pull the probe to the end of the hole. Each scan involved pulling the probe uphole at a rate of $1.5 \mathrm{~m} / \mathrm{min}$ by electric winch, with the entire scanning process taking six to seven hours per borehole.

At the same time the geological investigation was being planned, NRS ground control engineers were developing seismic monitoring plans for the NRD ramp and infrastructure. Communication between Geology, Ground Control, and ESG prior to ramp development resulted in a plan to use the pulley system to install sensors in the subhorizontal boreholes once the geological probe investigations were complete. Ground Control was confident that reasonable seismic coverage would be available from the main NRS array for the first few hundred metres of ramp development, but if successful, the longhole sensors would provide seismic monitoring coverage for the ramp and would become the backbone for the start of the NRD mining complex array. As a result, each of the nine scout-holes drilled ahead of the ramp face was instrumented with a twoinch diameter dual-element/high-sensitivity $15 \mathrm{~Hz}$ geophone. The sensors were installed at distances along the holes ranging from 400 to $450 \mathrm{~m}$, using the same pulley system that was used for the probes. Once in position, the sensor pods were grouted in place to ensure good coupling with the rock mass. The earliest scout-hole sensors were supplemented with shared sensors from the main NRS array that were gradually removed from the NRD network as new scout-hole sensors were installed and increasing source-tosensor distance eventually made them less effective.

The ramp development sensors will be important for seismic coverage for infrastructure development, shaft sinking, and early stage mining of the NRD orebody. These sensors will be supplemented with additional sensors installed in long vertical boreholes prior to shaft sinking to provide good 3D seismic monitoring coverage during the early stages of mining. The first of these vertical sensors has been installed and will be connected to the network once heavy equipment is finished with work in the hole collar area and the chance of sensor cable damage is minimized. Currently, the array is being used to monitor the twinned ramp and ongoing infrastructure development at NRD.

\section{Nickel Rim Deep Project - seismic monitoring results}

The main reason for ensuring adequate seismic monitoring coverage for the ramp development was to obtain information about the rock mass response to mining that could possibly provide early warning for development of a rockburst, such as an increase in seismic event rate. The seismic system at NRS is also used to determine when the rock mass has returned to more normal conditions after a large rockburst. It was expected that the NRD system would be used in the same manner for the ramp if a large seismic event was experienced. Secondary functions were to determine if specific geological structures were more seismically active than others, and whether differences in seismic nature could be observed between the geological units through which the ramp would be driven. The results had the potential to affect the ultimate location of the first ramp and the twinned secondary access ramp if problems related to seismicity were encountered and proved to be severe.

Ramp development started in May 2014, but it was determined that the first $200 \mathrm{~m}$ of drifting was close enough to the main NRS array for this system to be used to monitor the initial portion of the ramp. Once the first two scout-hole sensors were installed, a separate NRD network was created on the ESG system, consisting of the two $15 \mathrm{~Hz}$ dual-element triaxial geophones, supplemented with 15 uniaxial accelerometers, five triaxial $15 \mathrm{~Hz}$ geophones, and three uniaxial $15 \mathrm{~Hz}$ geophones shared with the main NRS array. Junction boxes for the scout-hole sensors contain one Paladin IVC data acquisition unit (six channels), allowing data collection from two of the triaxial sensors. Data transmission to surface is via fibre optic cable. The first seismic event recorded with the separate NRD array was on 9 October 2014. As the ramp moved further west from the NRS main array, more $15 \mathrm{~Hz}$ dual-element geophones were incrementally added as described above, and main array sensors were incrementally dropped from the NRD array when it was determined they were no longer contributing to the seismic event location solutions.

Figure 4 shows plan and sectional views of all blasting events recorded by the NRD seismic monitoring system from 9 October 2014 to 31 October 2016. Figure 5 shows plan and sectional views for all seismic events recorded and located during the same time period. Scout-hole and sensor positions are indicated in both figures. Fortunately, most of the seismic 


\section{Early access microseismic monitoring using sensors installed in long boreholes}

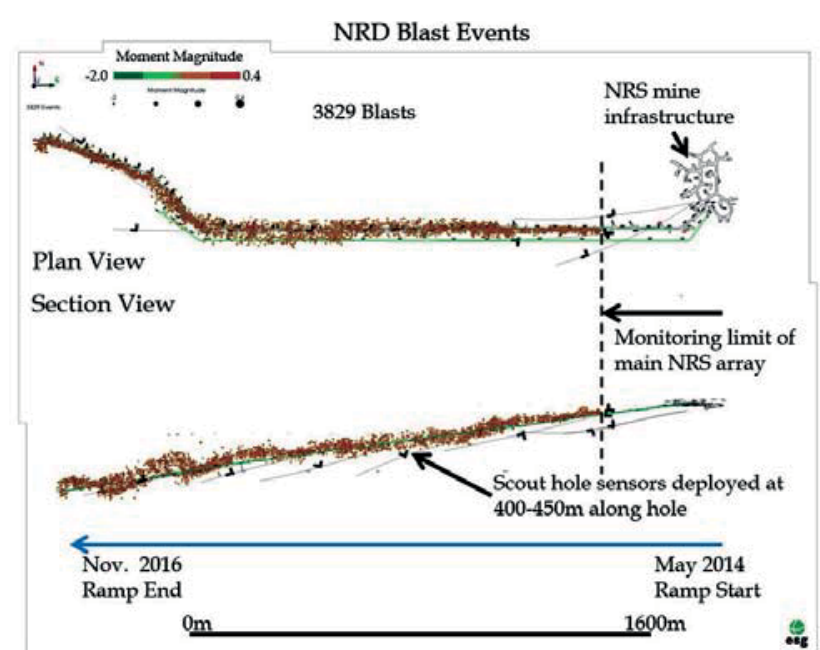

Figure 4-Plan and sectional views of blast events recorded by the NRD seismic monitoring system from 9 October 2014 to 31 October 2016

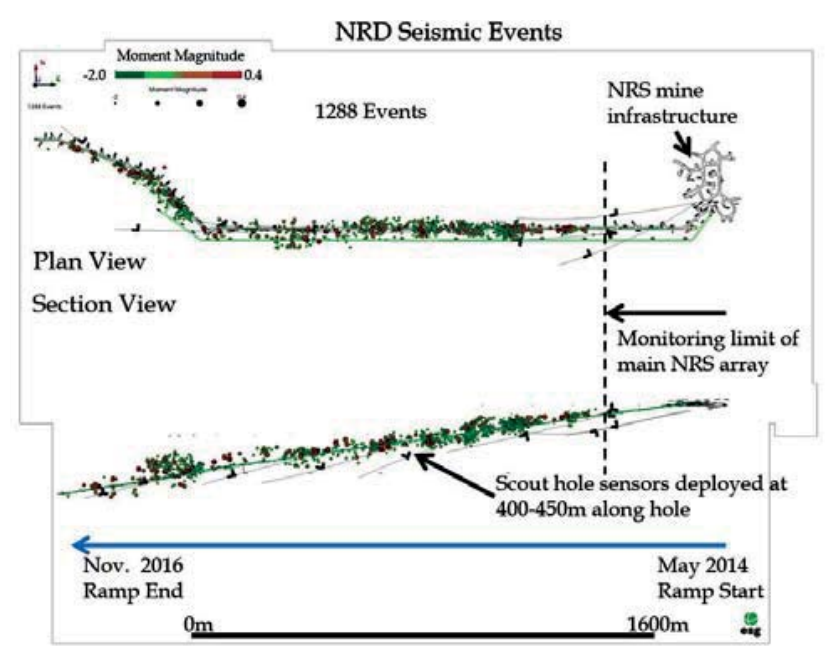

Figure 5-Plan and sectional views of seismic events recorded by the NRD seismic monitoring system from 9 October 2014 to 31 October 2016

events recorded by the NRD array were below moment magnitude 0.0 and no seismic events caused any significant damage during ramp development. There were no instances when workers were required to be removed from the heading.
In general, blasting and seismic events track the ramp development end well, with some scatter observed in the vertical during the latter stages of development as NRS main array sensors became less useful and were dropped from the $\mathrm{NRD}$ array. An unintended benefit was the use of the system by production managers for day-to-day ramp development planning. The ramp development was not tied to centralized blasting with the NRS mine due to the long distance between the NRD ramp and NRS main mining areas. A quick check of the seismic system allowed 'next shift' production managers to see at a glance if the previous shift had blasted. This saved time in underground planning for the next shift.

Table I shows the sensor status of the NRD seismic array at various dates throughout the project, and Figure 6 shows the number of uniaxial sensors used in the seismic event solution versus the event easting location. Uniaxial accelerometers from the main array were located at mine easting coordinates between E10000 and E10100. Figure 6 shows clearly that as ramp development progressed from an easting coordinate of E9700 to E7700 (2 km distance), the value of the uniaxial accelerometers in the array declined as fewer accelerometers were used in the seismic event solution. This was expected, as signal attenuation increases with sensor distance from the seismic event source. On 3 November 2015, with the ramp heading more than $1.4 \mathrm{~km}$ away, the last of the NRS main array sensors were removed

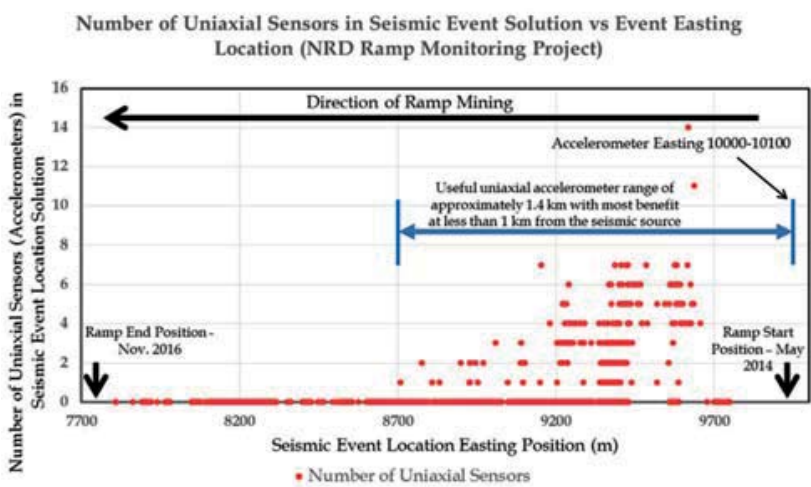

Figure 6-The number of uniaxial sensors included in the seismic event solution compared to the seismic event mine easting coordinate location. The data shows that uniaxial accelerometers are of most value when located less than $1 \mathrm{~km}$ from the seismic source

Table I

Sensor type distribution at various dates for the NRD seismic monitoring array

\begin{tabular}{|c|c|c|c|c|c|c|}
\hline \multirow[t]{2}{*}{ Date } & \multicolumn{2}{|c|}{ NRD array sensors } & \multicolumn{4}{|c|}{ NRS main array - supplemental sensors } \\
\hline & NRD Tri. 15 Hz geo.dual-E & NRD Tri. $15 \mathrm{~Hz}$ geo. std & NRS Tri. $15 \mathrm{~Hz}$ geo. std & NRS Uni. $15 \mathrm{~Hz}$ geo. & NRS Uni. accel. & Total sensors \\
\hline $\begin{array}{l}\text { Oct-14 } \\
\text { Mar-15 } \\
\text { Apr-15 } \\
\text { Jul-15 } \\
\text { Aug-15 } \\
\text { Oct-15 } \\
\text { Nov-15 } \\
\text { Mar-16 } \\
\text { Oct -16 } \\
\text { Dec-16 }\end{array}$ & $\begin{array}{l}2 \\
4 \\
5 \\
6 \\
6 \\
7 \\
7 \\
9 \\
9 \\
9\end{array}$ & $\begin{array}{l}0 \\
1 \\
1 \\
1 \\
1 \\
1 \\
1 \\
1 \\
1 \\
1\end{array}$ & $\begin{array}{l}5 \\
4 \\
2 \\
2 \\
2 \\
2 \\
2 \\
0 \\
0 \\
0 \\
0\end{array}$ & $\begin{array}{l}3 \\
1 \\
0 \\
0 \\
0 \\
0 \\
0 \\
0 \\
0 \\
0\end{array}$ & $\begin{array}{l}15 \\
5 \\
3 \\
3 \\
3 \\
3 \\
0 \\
0 \\
0 \\
0\end{array}$ & $\begin{array}{c}25 \\
15 \\
11 \\
12 \\
12 \\
13 \\
8 \\
10 \\
10 \\
10\end{array}$ \\
\hline
\end{tabular}




\section{Early access microseismic monitoring using sensors installed in long boreholes}

from the NRD array. This information is important for future monitoring requirements at NRD and for other projects in similar rock types such as ODP, as it indicates that the maximum benefit of the accelerometers is obtained at seismic source to sensor distances of less than $1 \mathrm{~km}$. Beyond $1 \mathrm{~km}$ distance between source and sensor, the signal to noise ratio becomes too low for the accelerometers to provide much useful information for small seismic events.

Although there was no overall change in the total number of sensors in the NRD array from March 2016 to December 2016, there were changes in the individual sensors used during this period. A single dual-element $15 \mathrm{~Hz}$ geophone sensor was installed in a $700 \mathrm{~m}$ long vertical borehole to provide some vertical offset from the linear nature of the array and improve seismic event locations in the vertical direction. This sensor operated briefly and was disconnected when it was found that the junction box was mounted in a place where further development for the twin ramp was required. This sensor will be reactivated once production operations are finished in the area. One of the earlier scouthole sensors was transferred to the NRS main array to help improve seismic locations of events recorded in the west side of NRS. Other factors influencing the sensitivity of the system and the nature of the data recorded included a triaxial sensor orientation calibration that was performed in December 2015. This calibration allowed the use of sensor orientations in the location algorithms and all previous data was reprocessed using this new algorithm.

The prime purpose of the seismic system was to help ensure the safety of workers at the ramp development face. All changes to the system were made with the intent of providing the best possible timely seismic information to mine personnel. Unfortunately, the changing system sensitivity over time makes seismic event data analysis somewhat more difficult, because it is not always clear if observations from the data are real or are influenced by changes in the seismic monitoring array. All observations discussed below consider the nature of the seismic array in assessing the data, and any conclusions are supported with underground observations from ground control engineers and workers at the face.

Figure 7 shows a plot of the cumulative event rate for all 1288 seismic events recorded by the NRD system and the event easting locations relative to time. The event easting locations generally track the ramp development heading with time, and show a change in slope from October 2015, when the ramp heading advance rate decreased when NRS production requirements took precedence over ramp face advance for NRS working crews.

The cumulative seismic events plotted in Figure 7 are not normalized for system sensitivity, but the large increase in event rate indicated coincides with the change in rock type intersected by the ramp. The ramp moved from the blocky, jointed hangingwall norite, with an unconfined compressive strength (UCS) of $200 \mathrm{MPa}$, into the stiffer footwall breccias (UCS $250 \mathrm{MPa}$ ) at E9570, and re-entered the norite at E8960. From past experience at NRS, a higher seismic event rate was expected in the breccia. Underground observations from workers indicated that the ground was 'working more' with more frequent audible 'pops' when the ramp was in the footwall breccia compared to the norite
Figure 8 shows the moment magnitude of seismic events plotted versus the easting position of the event. The general reduction in the number of low-magnitude events recorded with easting position is mostly a function of the loss of accelerometers with distance, as shown in Figure 6. The larger number of events recorded down to moment magnitude -1.4 between E8400 and E8200 coincides with the period when the ramp development intersected a more heavily faulted rock mass. These faults, dipping both east and west between $23^{\circ}$ and $65^{\circ}$, are shown on the included mine plan. The increase in event rate during this period is also indicated in Figure 7.

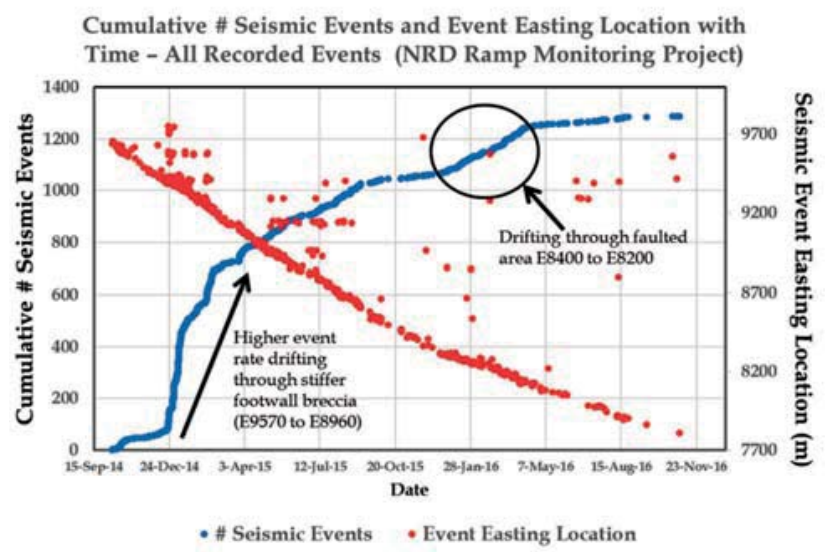

Figure 7-Cumulative number of seismic events and seismic event easting locations plotted with time for NRD ramp monitoring projec

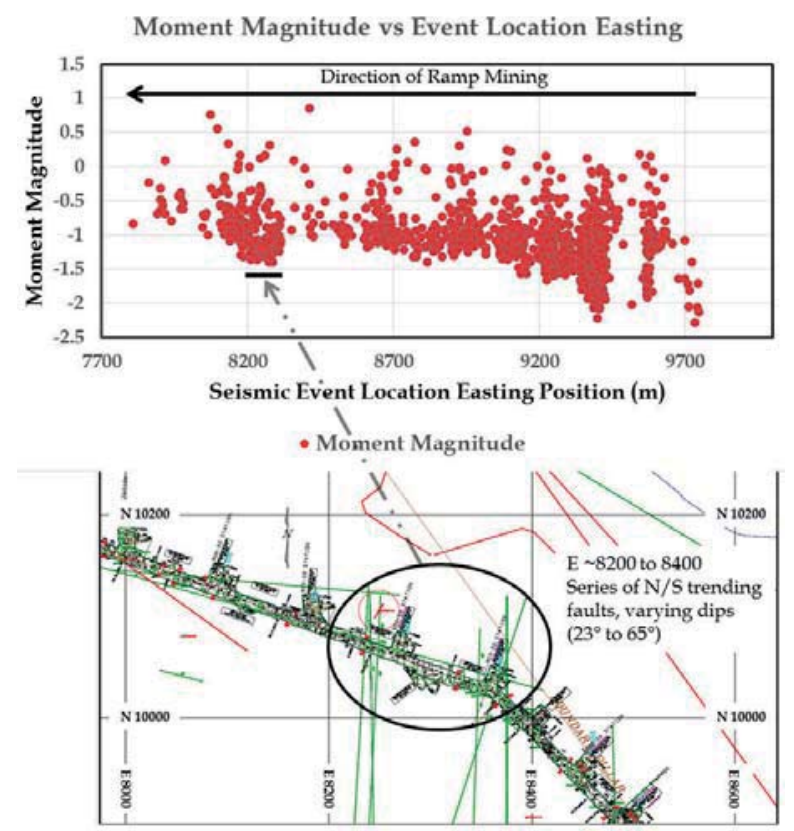

Figure 8-Moment magnitude of seismic events plotted as a function of event easting location. The event rate increased in the highlighted area due to a larger number of smaller seismic events recorded during the period the ramp intersected a series of faults between E8400 and E8200 


\section{Early access microseismic monitoring using sensors installed in long boreholes}

\section{Discussion and conclusions}

The first access to new mining areas is almost always via geological exploration/orebody delineation boreholes. These boreholes can be expensive to drill and it makes sense to make the best use of these holes for the benefit of the entire mining operation. For mines that expect to establish a seismic monitoring programme, once core has been obtained and geological investigations are completed, it is proposed that some of these holes be used for the placement of seismic sensors. With proper planning, these boreholes can be used to help establish a good 3D seismic monitoring array during, or even before, the first stages of mine infrastructure development.

The NRD ramp seismic monitoring project utilized existing geological boreholes to place seismic sensors ahead of the ramp development face. This system helped ensure that any abnormal seismic activity would be recorded and acted upon by mine management, thereby enhancing the safety of workers at the face. The existing NRD ramp monitoring system will be the starting point for ongoing seismic monitoring for infrastructure development for the NRD mine, including shaft sinking operations. Further longhole sensors will be added in new geological exploration boreholes to help provide good 3D coverage of the initial mine development and to provide rock mass deformation information to the ground control department very early in the mine's life. The same techniques are being implemented for Glencore's ODP project, with the first ODP ramp monitoring system being commissioned in February 2017.

Some results were presented from data recorded from the seismic monitoring of the NRD ramp development. Different seismic activity rates were detected as the ramp traversed different geological units with different rock mass strengths and jointing patterns. It was noted that ground control personnel and mine seismologists should consider the impact of changes to the seismic system when interpreting the seismic data.

The strategies and techniques for microseismic monitoring discussed in this paper should be considered for mines that are accessing the orebody from either the hangingwall or footwall alone, as at the Fraser Morgan mine. Quite often the seismic arrays monitoring these types of mines are planar in nature and/or only monitor one side of the mining due to lack of development access. Sensors could be installed in long boreholes to reach the opposite side of the orebody to improve 3D seismic coverage and provide more accurate seismic information.

The strategies discussed should also be considered for new mines developing from surface. The cost savings could be substantial if a seismic monitoring programme could take advantage of the long exploration boreholes drilled from surface for seismic sensor emplacement. There can be hundreds of long boreholes available during the exploration stage, often providing complete 3D access to the entire planned mining volume. Before grouting the holes closed, seismic sensors could be located in positions that will never be accessed again during the life of the mine. Currently, these are simply lost opportunities to create a seismic monitoring array with exceptional 3D coverage. The added advantage of early deployment of seismic monitoring for new mining projects is that background seismicity levels can be established for mines located in naturally seismically active areas.

Early seismic sensor placement at various elevations in exploration boreholes could also be highly beneficial to block caving mines and to mines with flat-lying deposits that suffer from limited access due to the planar nature of the mining. The ability to have sensors located above and below the mining horizon greatly improves the quality of the seismic data recorded.

Using surface boreholes for deep seismic sensor installation could also significantly reduce the quantity of seismic sensors required to be installed from within the mine. This could potentially eliminate the costs of a significant amount of seismic and communication hardware and cable, as well as the associated logistical costs to install and maintain this equipment underground.

\section{Acknowledgements}

The authors would like to thank Steve Falconer, Chris Goulet, Chris O'Connor and Ed Deneka from Sudbury Integrated Nickel Operations for their contributions to the NRD monitoring project. Ali Jalbout, formerly of Sudbury Integrated Nickel Operations, was instrumental in organizing the first implementation of the scout-hole sensor deployments and spearheading the start of the NRD monitoring project. Dave Collins and the ESG Advanced Analysis Group performed the triaxial sensor orientation and calibration.

The authors would also like to thank Glencore and ESG management for their support in implementing innovative solutions using new technologies.

\section{References}

BECK, D.A. and BRADY, B.H.G. 2001. Evaluation and application of controlling parameters for seismic events in hard-rock mines. International Journal of Rock Mechanics and Mining Sciences, vol. 39, no. 5. pp. 633-642. doi: 10.1016/S1365-1609(02)00061-8

Hudyma, M. and BenetEAu, D. 2010. Sudbury regional seismic network. Proceedings of the CIM Maintenance Engineering and Mine Operators Conference, Sudbury, Ontario. CIM, Montreal.

SiMSER, B. and ButLER, T. 2016. Ground support practice at Glencore's nickel rim south mine - with a link to seismic monitoring data. Proceedings of the Eighth International Symposium on Ground Support in Mining and Underground Construction, Luleå University of Technology, Luleå, Sweden. Nordlund, E., Jones T.H., and Eitzenberger, A. (eds.). Luleå University of Technology.

Simser, B., Deredin, R., Jalbout, A., and Butler, T. 2015. Use of microseismic monitoring data as an aid to rock mechanics decision making and mine design verification. Proceedings of the 49th US Rock Mechanics/Geomechanics Symposium, San Francisco, CA, 28 June-1 July. American Rock Mechanics Association, Alexandria, VA. Paper 15-374.

Sweby, G., Trifu, C., Goodchild, D., and Morris, L. 2006. High resolution seismic monitoring at Mt. Keith open pit mine. Proceedings of the 41st US Rock Mechanics Symposium, Golden, CO. American Rock Mechanics Association, Alexandria, VA. Paper 06-1159.

TRIfu, C-I., Shumila, V., and Leslie, I. 2008. Application of joint seismic event location techniques at Chuquicamata open pit mine, Chile. MassMin 2008 - Proceedings of the 5th International Conference and Exhibition on Mass Mining, Lulea, Sweden, 9-11 June 2008. Schunnesson, H. and Nordlund, E. (eds.). Lulea University of Technology. pp. 943-952. 